\title{
Risk factors and management of positive horizontal margin in early gastric cancer resected by en bloc endoscopic submucosal dissection
}

\author{
Norifumi Numata $\cdot$ Shiro Oka $\cdot$ Shinji Tanaka $\cdot$ \\ Kenichi Kagemoto $\cdot$ Yoji Sanomura $\cdot$ Shigeto Yoshida $\cdot$ \\ Koji Arihiro $\cdot$ Fumio Shimamoto $\cdot$ Kazuaki Chayama
}

Received: 28 October 2013/Accepted: 9 March 2014/Published online: 16 April 2014

(c) The International Gastric Cancer Association and The Japanese Gastric Cancer Association 2014

\begin{abstract}
Background Although endoscopic submucosal dissection (ESD) is a widely accepted treatment for early gastric cancer (EGC), there is no consensus regarding the management of positive horizontal margin (HM) despite en bloc ESD. The aim of the current study was to identify the risk factors and optimal management of positive $\mathrm{HM}$ in EGCs resected by en bloc ESD.

Methods A total of 890 consecutive patients with 1,053 intramucosal EGCs resected by en bloc ESD between April 2005 and June 2011. Clinicopathological data were retrieved retrospectively to assess the positive HM rate, local recurrence rate, risk factors for positive HM, and outcomes of treatment for local recurrent tumor. Positive HM was defined as a margin with direct tumor invasion (type A), the presence of cancerous cells on either end of 2-mm-thick cut sections (type B), or an unclear tumor margin resulting from crush or burn damage (type $\mathrm{C}$ ).
\end{abstract}

\footnotetext{
N. Numata $\cdot$ K. Kagemoto $\cdot$ K. Chayama Department of Gastroenterology and Metabolism, Graduate School of Biomedical Sciences, Hiroshima University, Hiroshima, Japan

e-mail: nnumata@hiroshima-u.ac.jp

S. Oka $(\bowtie) \cdot$ S. Tanaka $\cdot$ Y. Sanomura $\cdot$ S. Yoshida

Department of Endoscopy, Hiroshima University Hospital, Hiroshima, Japan

e-mail: oka4683@hiroshima-u.ac.jp

K. Arihiro

Department of Pathology, Hiroshima University Hospital,

Hiroshima, Japan

F. Shimamoto

Faculty of Human Culture and Science,

Prefectural University of Hiroshima, Hiroshima, Japan
}

Results The positive HM rate was $2.0 \%(21 / 1,053)$. The local recurrence rate was $0.3 \%(3 / 1,053)$. All local recurrent tumors were intramucosal carcinomas, and were resected curatively by re-ESD. Multivariate analysis with logistic regression showed tumor location in the upper third of the stomach and lesions not matching the absolute indication to be independent risk factors for positive HM. Conclusion The risk factors for HM positivity in cases of EGC resected by en bloc ESD are tumor location in the upper third of the stomach and dissatisfaction of the absolute indication for curative ESD.

Keywords Early gastric cancer - Endoscopic submucosal dissection $\cdot$ Horizontal margin

\section{Introduction}

Endoscopic submucosal dissection (ESD) is widely accepted for early gastric cancer (EGC), and it can be performed regardless of tumor size, location, or fibrosis [1-11]. According to the Japanese Gastric Cancer Association (JGCA), [12] the absolute indication for curative ESD are well- or moderately differentiated intramucosal adenocarcinoma $\leq 2 \mathrm{~cm}$ in diameter without ulceration and absence of lymph node (LN) metastasis and lymphatic vessel invasion. Expanded indications include well- or moderately differentiated intramucosal adenocarcinoma $>2 \mathrm{~cm}$ in diameter without ulceration, wellor moderately differentiated adenocarcinoma $\leq 3 \mathrm{~cm}$ in diameter with submucosa invasion $<500 \mu \mathrm{m}$ without ulceration, well- or moderately differentiated adenocarcinoma with ulceration, and undifferentiated intramucosal adenocarcinoma $\leq 2 \mathrm{~cm}$ in diameter without ulceration.

We have possibly seen an increase in the number of ESD for EGC and a corresponding increase in the number of en bloc 
specimens with positive horizontal margin (HM). However, there is no consensus regarding the management of positive HM. In a retrospective study, we evaluated the specimens after en bloc ESD for intramucosal EGC to identify risk factors and to determine the best management strategy for positive $\mathrm{HM}$ in cases of EGC resected by en bloc ESD.

\section{Patients and methods}

Patients

The study group comprised 890 consecutive patients with 1,053 intramucosal EGCs resected by en bloc ESD at Hiroshima University Hospital between April 2005 and June 2011 (Fig. 1). We classified the lesions by the HM, whether positive $(n=21)$ or negative $(n=1,032)$. The indications for ESD were based on the expectation that the procedure would be curative, as set out in the Japanese classification of gastric carcinoma issued by the JGCA [12]. This study was carried out with approval from the institutional review board of Hiroshima University (No. 658), and all patients provided written informed consent for the ESD procedure and follow-up assessment.

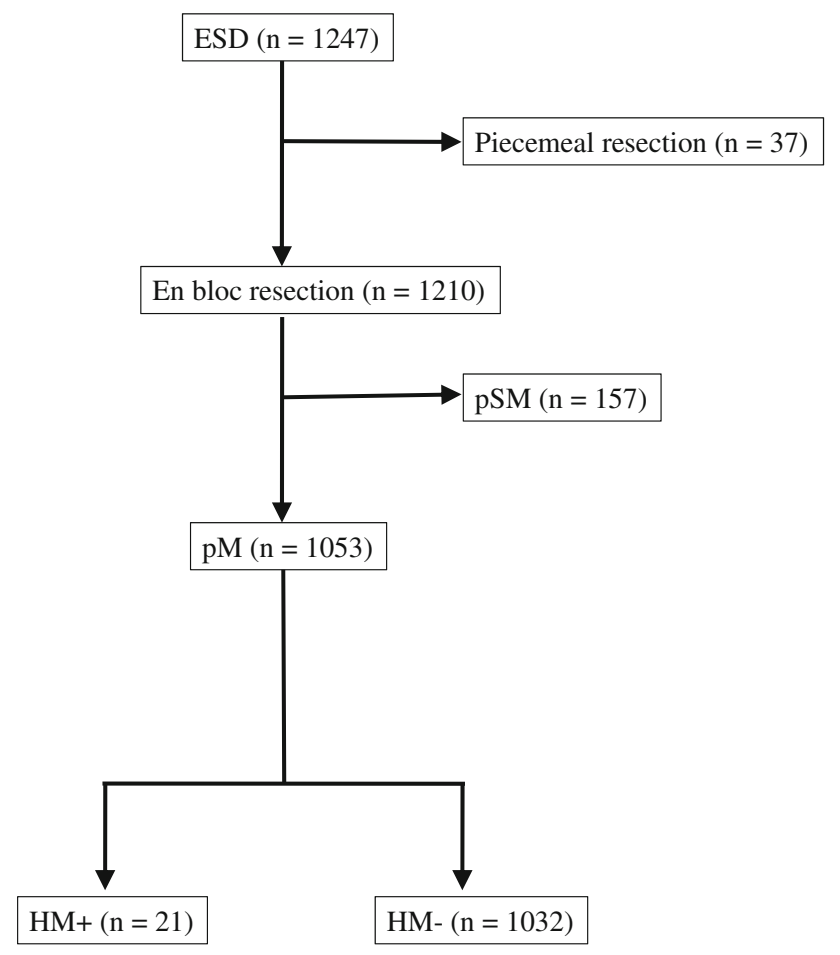

Apr. 2005 - June. 2011

Fig. 1 Flowchart showing the 1,053 ESD cases used in the study. $E S D$ endoscopic submucosal dissection, $p M$ pathologic intramucosal carcinoma, pSM pathologic submucosal invasive carcinoma, $H M$ horizontal margin
ESD procedure

ESD was performed with a conventional single-channel endoscope (GIF-450RD5, FUJIFILM Medical, Tokyo, Japan; GIF-H260, -H260Z, or -Q260J, Olympus, Tokyo, Japan) or a two-channel endoscope (GIF-450D5, FUJIFILM Medical; or 2TQ260M; Olympus), as reported previously [5, 6, 8, 9, 13]. Between April 2005 and September 2009, we identified the tumor demarcation line (DL) by white light endoscopy and chromoendoscopy. And, starting in October 2009, we used magnifying endoscopy with narrow band imaging (NBI) together with white light endoscopy and chromoendoscopy. When the demarcation line was unclear with endoscopy examination, we had negative biopsy around the lesion. After recognizing the DL, marking dots were placed around the lesion using an argon plasma coagulation probe. When the tumor were well- or moderately differentiated adenocarcinoma, marking dots were made $5 \mathrm{~mm}$ from the DL, and when the tumor were undifferentiated adenocarcinoma the marking dots were at least $10 \mathrm{~mm}$ from DL. The ESD procedure was performed mainly with the IT knife/IT knife 2 and an electrosurgical generator (ICC 200 or VIO 300D, Erbe, Tubingen, Germany; or ESG 100, Olympus). We used a needle knife for a 1- to 2-mm precut, and we performed a circumferential mucosal incision $5 \mathrm{~mm}$ outside the marking with the IT knife/IT Knife2. We performed preventative coagulation for all exposed vessels on the artificial ulcer with hemostatic forceps (FD-410LR, Olympus; or HDB2418W-W, Pentax, Tokyo, Japan) upon completion of ESD [13]. Poor control of bleeding during ESD was defined as bleeding that required multiple coagulations (10 times), as reported previously [13]. In all patients, the presence or absence of submucosal fibrosis was assessed under white light conventional endoscopy and chromoendoscopy. Endoscopic findings were classified according to the system previously reported [8, 14], and based on observations at the time of injection of sodium hyaluronate with indigo carmine: $F 0$, no fibrosis, which manifests as a blue transparent layer; $F 1$, mild fibrosis, which appears as a white web-like structure in the blue submucosal layers; and $F 2$, severe fibrosis, which appears as a white muscular structure without a blue transparent layer in the submucosal layers. The white muscular structure is similar to the muscular layer; therefore, this structure cannot be easily separated from the muscular layer.

Pathologic evaluation of resected specimens

The resected specimen was fixed in formalin solution and cut into 2-mm-thick sections. Histopathologic diagnosis was based on the Japanese Classification of Gastric Carcinoma [15]. Positive HM was defined as a margin directly 
Type A

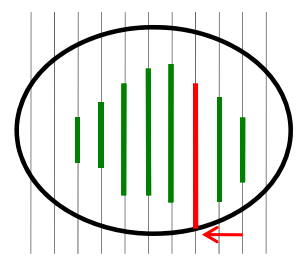

Type B

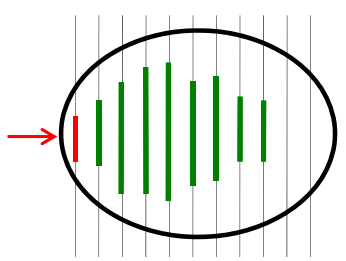

Type C

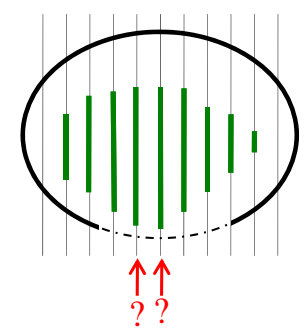

Crush/burn damage

Fig. 2 Types of positive horizontal margins. Type $A$ positive horizontal margin was defined as a margin directly infiltrated by tumor cells. Type $B$ the presence of cancerous cells on either side of the 2-mm-thick sections. Type $C$ tumor margin that could not be evaluated because of crush or burn damage

infiltrated by tumor cells (type A) or the presence of cancerous cells on either side of the 2-mm-thick sections (type B), or tumor margin that could not be evaluated because of crush or burn damage (type C) (Fig. 2).

According to the Japanese Gastric Cancer Association (JGCA), [12] the absolute indication for curative ESD are well- or moderately differentiated intramucosal adenocarcinoma $\leq 2 \mathrm{~cm}$ in diameter, no ulceration, and absence of lymph node metastasis and lymphatic vessel invasion. The expanded indications add well- or moderately differentiated intramucosal adenocarcinoma $>2 \mathrm{~cm}$ in diameter without ulceration, well- or moderately differentiated adenocarcinoma $\leq 3 \mathrm{~cm}$ in diameter and invading the submucosa $<500 \mu \mathrm{m}$ without ulceration, and well- or moderately differentiated adenocarcinoma with ulceration.

\section{Patient follow-up}

Follow-up endoscopy after ESD was performed immediately when positive HM was found by pathologic diagnosis, and, if there was no local recurrence, surveillance endoscopy was performed at 3-6 months, at 12 months, and every 12 months thereafter. When the HM was negative, follow-up endoscopy was performed every
12 months. Biopsy of the ESD scar site was always performed, whether or not local recurrent tumor was observed endoscopically.

Outcome measures

Clinicopathological characteristics of the positive HMs, the incidence of positive HM, incidence of local recurrence, risk factors for positive $\mathrm{HM}$, characteristics of local recurrent tumors, and outcomes of treatment for local recurrent tumors were evaluated.

Statistical analysis

Differences between lesions with positive HM and those with a negative $\mathrm{HM}$ or between the various types of positive margins were analyzed by $\chi^{2}$ test with Yates' correction, by Fisher's exact test, or Student's $t$ test. $P<0.05$ was considered significant.

\section{Results}

Clinical characteristics of the $21 \mathrm{HM}$-positive lesions are shown in Table 1. Tumor location in the upper third of the stomach, the presence of severe fibrosis, and the ESD specimen not meeting the absolute indication were significantly more frequent among lesions with positive HM than among lesions with a negative HM. Six of the lesions were $>2 \mathrm{~cm}$ in diameter, and three had ulceration $\leq 3 \mathrm{~cm}$ diameter. All three lesions with non-curative indication were undifferentiated adenocarcinomas $>2 \mathrm{~cm}$ in diameter. These three lesions were considered as the expanded indication cases prior to ESD (within $2 \mathrm{~cm}$ in size); however, pathological findings showed the resected lesion as over $2 \mathrm{~cm}$ (non-curative indication). All cases were intramucosal undifferentiated carcinoma without ulceration and vessel involvement.

Multivariate analysis with logistic regression showed tumor location in the upper third of the stomach and tumor characteristics not meeting the absolute indication to be independent risk factors for positive HM (Table 2).

EGCs with positive HM are shown per margin type in Table 3. Five lesions had a type A margin, 9 had a type B margin, and 7 had a type $C$ margin. Tumor location in the upper third of the stomach was significantly more frequent in association with type $\mathrm{A}$ and $\mathrm{C}$ margins than in association with type $\mathrm{B}$ margins. Magnifying endoscopy with NBI identified the demarcation line significantly more frequently in lesions with a type $\mathrm{A}$ or type $\mathrm{B}$ margin than in lesions with a type $\mathrm{C}$ margin. No local recurrent tumor was found in association with type $\mathrm{C}$ margins, but the difference between types was not significant. 
Table 1 Characteristics of EGCs (pM) treated by ESD

\begin{tabular}{llll}
\hline Variable & $\begin{array}{l}\text { No. of } \\
\text { cases }\end{array}$ & $\begin{array}{l}\text { No. of HM-positive } \\
\text { cases }\end{array}$ & $P$ value \\
\hline
\end{tabular}

Location

$\begin{array}{lll}\mathrm{U} & 141 & 9(6.4) \\ \mathrm{M} & 296 & 7(2.3) \\ \mathrm{L} & 616 & 5(0.8)\end{array}$

Tumor size (mm)

$\begin{array}{lrr}\leq 20 & 838 & 15(1.8) \\ \geq 21 & 215 & 6(2.8)\end{array}$

Macroscopic type

$\begin{array}{lrr}\text { Elevated } & 562 & 12(2.1) \\ \text { Depressed } & 491 & 9(1.8) \\ \begin{array}{l}\text { Histologic type } \\ \text { Intestinal }\end{array} & 1,007 & 18(1.8) \\ \text { Diffuse } & 46 & 3(6.5) \\ \text { NBI magnification } & & \\ (+) & 427 & 12(2.3) \\ (-) & 626 & 9(1.4)\end{array}$

Control of bleeding during ESD

$\begin{array}{lrr}\text { Good } & 914 & 15(1.6) \\ \text { Poor } & 139 & 6(4.3)\end{array}$

Degree of fibrosis during ESD

$\begin{array}{rrr}F 0 & 812 & 12(1.5) \\ F 1 & 155 & 4(2.6) \\ F 2 & 86 & 5(5.9)\end{array}$

Histologic ulceration

$\begin{array}{rrr}(+) & 63 & 4(6.5) \\ (-) & 991 & 17(1.7)\end{array}$

Indication for ESD

$\begin{array}{lrl}\text { Absolute } & 772 & 9(1.2) \\ \text { Expanded } & 259 & 9(3.5) \\ \text { Non-curative } & 22 & 3(13.6)\end{array}$

Local recurrent tumor

\begin{tabular}{rrrr}
$(+)$ & 3 & $3(100)$ & $<0.01$ \\
$(-)$ & 1,050 & $18(1.7)$ & \\
Total & 1,053 & $21(2.0)$ & \\
\hline
\end{tabular}

$p M$ pathologic intramucosal carcinoma, $U$ upper third of the stomach, $M$ middle third of the stomach, $L$ lower third of the stomach

Table 2 Results of multivariate logistic regression analysis of risk factors for positive horizontal margin

\begin{tabular}{lll}
\hline Factor & $\begin{array}{l}\text { Odds ratio } \\
(95 \% \mathrm{CI})\end{array}$ & $P$ value \\
\hline $\begin{array}{l}\text { Location (U vs. M/L) } \\
\begin{array}{l}\text { Indication for ESD (expanded/non- } \\
\text { curative vs. absolute) }\end{array}\end{array}$ & $\begin{array}{l}2.10(1.60-10.1) \\
\text { Endoscopic fibrosis }(F 2 \text { vs. } F 0 / 1)\end{array}$ & $<0.01$ \\
\hline
\end{tabular}

$U$ upper third of the stomach, $M$ middle third of the stomach, $L$ lower third of the stomach
Table 3 Characteristics of EGCs with positive horizontal margin $(n=21)$, shown per margin type

\begin{tabular}{lllll}
\hline Variable & Type A & Type B & Type C & $P$ value \\
\hline Location & & & & \\
$\mathrm{U}$ & 3 & 1 & 5 & $<0.05$ \\
$\mathrm{M}+\mathrm{L}$ & 2 & 8 & 2 &
\end{tabular}

Tumor size $(\mathrm{mm})$

$\begin{array}{rllll}\leq 20 & 3 & 6 & 6 & \text { NS } \\ \leq 21 & 2 & 3 & 1 & \\ \text { Color } & & & & \end{array}$

$\begin{array}{llll}\text { Normal } & 1 & 4 & 2 \\ \text { Pale } & 2 & 1 & 4 \\ \text { Reddish } & 2 & 4 & 1\end{array}$

Atrophy

$\begin{array}{llll}\text { Close } & 2 & 0 & 1 \\ \text { Open } & 3 & 9 & 6\end{array}$

NS

Macroscopic type

$\begin{array}{llll}\text { Elevated } & 3 & 5 & 4 \\ \text { Depressed } & 2 & 4 & 3\end{array}$

NS

Concomitant IIb

$\begin{array}{lllll}(+) & 0 & 0 & 0 & \text { NS } \\ (-) & 5 & 9 & 7 & \end{array}$

Histologic type

$\begin{array}{lllll}\text { Intestinal } & 4 & 9 & 7 & \text { NS } \\ \text { Diffuse } & 1 & 0 & 0 & \end{array}$

Mucin phenotype

$\begin{array}{lllll}\text { Gastric type } & 4 & 4 & 1 & \text { NS } \\ \text { Intestinal type } & 1 & 2 & 2 & \end{array}$

$\begin{array}{llll}\text { Mixed type } & 0 & 3 & 4\end{array}$

INF

$\begin{array}{llll}a & 3 & 8 & 6 \\ b & 2 & 1 & 1 \\ c & 0 & 0 & 0\end{array}$

NS

NBI magnification

$\begin{array}{lllll}(+) & 3 & 8 & 1 & <0.05 \\ (-) & 2 & 1 & 6 & \end{array}$

Control of bleeding during ESD

$\begin{array}{lllll}\text { Good } & 3 & 7 & 5 & \text { NS } \\ \text { Poor } & 2 & 2 & 2 & \end{array}$

Degree of fibrosis during ESD

$\begin{array}{lllll}F 0+F 1 & 3 & 8 & 5 & \text { NS } \\ F 2 & 2 & 1 & 2 & \end{array}$

Histologic ulceration

$\begin{array}{lllll}(+) & 1 & 1 & 2 & \text { NS } \\ (-) & 4 & 8 & 5 & \end{array}$

Local recurrent tumor

$\begin{array}{rrrrr}(+) & 2 & 1 & 0 & \text { NS } \\ (-) & 3 & 8 & 7 & \\ \text { Total } & 5 & 9 & 7 & \end{array}$

$U$ upper third of the stomach, $M$ middle third of the stomach, $L$ lower third of the stomach, INF infiltrative growth 
Table 4 Characteristics of the HM-positive cases which occurred the local recurrent tumor

\begin{tabular}{lllllllllll}
\hline Patients & Location & $\begin{array}{l}\text { Tumor } \\
\text { size } \\
(\mathrm{mm})\end{array}$ & $\begin{array}{l}\text { Macroscopic } \\
\text { type }\end{array}$ & $\begin{array}{l}\text { Histologic } \\
\text { type }\end{array}$ & $\begin{array}{l}\text { Degree of } \\
\text { fibrosis }\end{array}$ & $\begin{array}{l}\text { UL } \\
\text { of HM }\end{array}$ & $\begin{array}{l}\text { Time to } \\
\text { recurrence } \\
\text { (months) }\end{array}$ & $\begin{array}{l}\text { Additional } \\
\text { treatment }\end{array}$ & $\begin{array}{l}\text { Recurrence after } \\
\text { additional ESD }\end{array}$ \\
\hline $\begin{array}{c}\begin{array}{c}\text { 6-year- } \\
\text { old male }\end{array} \\
\text { U U }\end{array}$ & 25 & Elevated & Mod & $F 0$ & $(-)$ B & 11 & ESD & $(-)$ \\
$\begin{array}{c}73 \text {-year- } \\
\text { old male }\end{array}$ & $\mathrm{U}$ & 100 & Elevated & Pap & $F 0$ & $(-)$ A & 8 & ESD & $(-)$ \\
$\begin{array}{c}58 \text {-year- } \\
\text { old } \\
\text { female }\end{array}$ & $\mathrm{U}$ & 20 & Elevated & Mod & $F 0$ & $(-)$ A & 34 & ESD & $(-)$ \\
\hline
\end{tabular}

$U$ upper third of the stomach, Mod moderately differentiated adenocarcinoma, Pap papillary adenocarcinoma, $U L$ ulceration, $H M$ horizontal margin, ESD endoscopic submucosal dissection

${ }^{\text {a }}$ Observed during ESD

Characteristics of the three HM-positive cases, which occurred the local recurrent tumor, are shown in Table 4. All local recurrent tumors were resected curatively by additional ESD. The times to discovery of local recurrent tumor were 11,8 , and 34 months.

\section{Discussion}

In the present study, the incidence of positive HM in en bloc specimens of intramucosal adenocarcinoma resected by ESD was $2.0 \%$, and the incidence of local recurrence in HM-positive cases was $14.3 \%$. Kakushima et al. [16] reported that the diameter of the tumor, recurrent-type cancer, submucosal cancer, and undifferentiated-type cancer were risk factors for positive HM in cases of EGC, including submucosal carcinoma, resected by ESD. AsadaHirayama et al. [17] reported that a flat component, a large lesion, and moderately differentiated adenocarcinoma are factors predictive of inaccurate endoscopic assessment of the horizontal extent of intestinal-type EGC. In the present study, we limited the lesions to intramucosal adenocarcinomas resected by en bloc ESD so that we could accurately determine the number of lesions for which curative resection was achieved.

Tumor location in the upper third of the stomach and a lesion not meeting the absolute indication were shown to be risk factors for positive HM. Identification of the demarcation line was more difficult in these lesions. In addition, crush or burn damage occurred most often in these lesions, which can result in an unclear HM. Lesions with direct HM infiltration (type A) or with cancerous cells on either sides of the specimen (type B) were prone to local recurrence. Thus, a type $\mathrm{A}$ or type $\mathrm{B}$ pathologic diagnosis requires strict follow-up. The majority $(71.4 \%, 5 / 7)$ of lesions with an unclear tumor margin attributed to crush or burn damage (type C) existed in the upper third of the stomach. We think that the technical difficulty of ESD in the upper third of the stomach explains the frequency of such crush or burn damage. We had been practicing ESD approximately 7 years before we began using magnifying endoscopy with NBI, so our ESD technique was advanced, thus reducing the potential for crush and burn. This might explain our relatively low number of type $\mathrm{C}$ cases with magnifying endoscopy with NBI. No local recurrent tumor was found in association with a type C HM, so we think that our type $\mathrm{C}$ cases were misdiagnosed as HM-positive because of the crush or burn effect. To reduce the number of type $\mathrm{C}$ assessments, it will be necessary to devise a marking system that accounts for the crush or burn effect and to further improve the ESD procedure. Crush or burn damage occurred most often in the upper third of the stomach, therefore we think it is better to make marking dots enough away from DL of the lesions in the upper third of the stomach compared with the lesions in the other locations to reduce the type C HM cases.

There are various types of HM positivity so specimens that are HM-positive should be further evaluated according to the type-based risk of local recurrence.

ESD was developed for the purpose of reducing the incidence of local recurrence associated with endoscopic mucosal resection (EMR), [18-21], but local recurrence remains problematic. Takenaka et al. [22] identified tumor size $>30 \mathrm{~mm}$, tumor location in the upper third of the stomach, and incomplete resection as factors significantly associated with local recurrence. In the present study, the incidence of local recurrence was significantly higher in cases of positive HM than cases of a negative HM.

In cases of local recurrence, severe fibrosis after endoscopic resection makes the depth of invasion difficult to determine, $[23,24]$ and there is a high risk of perforation in such cases $[3,25,26]$, so the usefulness of laparoscopic surgery for local recurrence has been reported [27-29]. However, we have reported that ESD, which is far less invasive than surgical resection, can be performed safely for local recurrence after EMR [6] or ESD [8], and we 
believe that even recurrent intramucosal carcinoma after ESD for intramucosal EGC is an indication for re-ESD. However, when a local recurrent tumor proves to be a submucosal invasive carcinoma or undifferentiated adenocarcinoma, surgical resection should be considered.

In conclusion, to reduce the incidence of positive HMs, it will be important to improve (1) the diagnostic performance of magnifying endoscopy in identifying the demarcation line, (2) the ESD procedure itself, and (3) the specimen handling technology. When positive $\mathrm{HM}$ is found, it is important to consider the margin type and to conduct appropriate follow-up. Instead of performing surgical resection as soon as positive HM is found, we should perform strict surveillance and consider whether re-ESD is possible if the local recurrence proves to be a differentiated intramucosal carcinoma. In addition, a prospective randomized controlled trial that involves many patients is needed so that enough data can be obtained to set appropriate surveillance intervals.

\section{References}

1. Gotoda T, Kondo H, Ono H, Saito Y, Yamaguchi H, Saito D, et al. A new endoscopic mucosal resection procedure using an insulation-tipped electrosurgical knife for rectal flat lesions: report of two cases. Gastrointest Endosc. 1999;50:560-3.

2. Ono H, Kondo H, Gotoda T, Shirao K, Yamaguchi H, Saito D, et al. Endoscopic mucosal resection for treatment of early gastric cancer. Gut. 2001;48:225-9.

3. Oda I, Gotoda T, Hamanaka H, Eguchi T, Saito Y, Matsuda T, et al. Endoscopic submucosal dissection for early gastric cancer: technical feasibility, operation time and complications from a large consecutive series. Dig Endosc. 2005;17:54-8.

4. Fujishiro M, Yahagi N, Nakamura M, Kakushima N, Kodashima $\mathrm{S}$, Ono $\mathrm{S}$, et al. Successful outcomes of a novel endoscopic treatment for GI tumors: endoscopic submucosal dissection with a mixture of high-molecular-weight hyaluronic acid, glycerin, and sugar. Gastrointest Endosc. 2006;63:243-9.

5. Oka S, Tanaka S, Kaneko I, Mouri R, Hirata M, Kawamura T, et al. Advantage of endoscopic submucosal dissection compared with EMR for early gastric cancer. Gastrointest Endosc. 2006;64: 877-83.

6. Oka S, Tanaka S, Kaneko I, Mouri R, Hirata M, Kanao H, et al. Endoscopic submucosal dissection for residual/local recurrence of early gastric cancer after endoscopic mucosal resection. Endoscopy. 2006;38:996-1000.

7. Imagawa A, Okada H, Kawahara Y, Takenaka R, Kato J, Kawamoto $\mathrm{H}$, et al. Endoscopic submucosal dissection for early gastric cancer: results and degrees of technical difficulty as well as success. Endoscopy. 2006;38:987-90.

8. Higashiyama M, Oka S, Tanaka S, Sanomura Y, Yoshida S, Hiyama T, et al. Outcome of endoscopic submucosal dissection for gastric epithelial neoplasm in relationship to endoscopic classifications of submucosal fibrosis. Gastric Cancer. 2013;16: 404-10.

9. Higashiyama M, Oka S, Tanaka S, Numata N, Sanomura Y, Yoshida S, et al. Endoscopic submucosal dissection for residual early gastric cancer after endoscopic submucosal dissection. Gastrointest Endosc. 2012;77:298-302.

10. Sanomura Y, Oka S, Tanaka S, Noda I, Higashiyama M, Imagawa $\mathrm{H}$, et al. Clinical validity of endoscopic submucosal dissection for submucosal invasive gastric cancer: a single-center study. Gastric Cancer. 2012;15:97-105.

11. Hirasawa T, Gotoda T, Miyata S, Kato Y, Shimoda T, Taniguchi $\mathrm{H}$, et al. Incidence of lymph node metastasis and the feasibility of endoscopic resection for undifferentiated-type early gastric cancer. Gastric Cancer. 2009;12:148-52.

12. Association Japanese Gastric Cancer. Japanese gastric cancer treatment guidelines 2010 (ver. 3). Gastric Cancer. 2011;14: $113-23$.

13. Higashiyama $M$, Oka $S$, Tanaka $S$, Sanomura $Y$, Imagawa $H$, Shishido $\mathrm{T}$, et al. Risk factors for bleeding after endoscopic submucosal dissection of gastric epithelial neoplasm. Dig Endosc. 2011;23:290-5.

14. Matsumoto A, Tanaka S, Oba S, et al. Outcome of endoscopic submucosal dissection for colorectal tumors accompanied by fibrosis. Scand J Gastroenterol. 2010;45:1329-37.

15. Association Japanese Gastric Cancer. Japanese classification of gastric carcinoma: 3rd English edition. Gastric Cancer. 2011;14: 101-12.

16. Kakushima A, Ono H, Tanaka M, Kanao H, Oka S, Yoshihara M, et al. Factors related to lateral margin positivity for cancer in gastric specimens of endoscopic submucosal dissection. Dig Endosc. 2011;23:227-32.

17. Asada-Hirayama I, Kodashima S, Goto O, Yamamichi N, Ono S, Niimi K, et al. Factors predictive of inaccurate determination of horizontal extent of intestinal-type early gastric cancers during endoscopic submucosal dissection: a retrospective analysis. Dig Endosc. doi:10.1111/den.12043.

18. Watanabe K, Ogata S, Kawazoe S, Watanabe K, Koyama T, Kajiwara T, et al. Clinical outcomes of EMR for gastric tumors: historical pilot evaluation between endoscopic submucosal dissection and conventional mucosal resection. Gastrointest Endosc. 2006:776-82.

19. Ohkuwa M, Hosokawa K, Boku N, Ohtu A, Tajiri H, Yoshida S. New endoscopic treatment for intramucosal gastric tumors using an insulated-tip diathermic knife. Endoscopy. 2001;33:221-6.

20. Urabe Y, Hiyama Y, Tanaka S, Yoshihara M, Arihiro K, Chayama K. Advantages of endoscopic submucosal dissection versus endoscopic oblique aspiration mucosectomy for superficial esophageal tumors. J Gastroenterol Hepatol. 2011;26:275-80.

21. Tanaka S, Oka S, Chayama K. Colorectal endoscopic submucosal dissection: present status and future perspective, including its differentiation from endoscopic mucosal resection. J Gastroenterol. 2008;43:641-51.

22. Takenaka R, Kawahara Y, Okada H, Hori K, Inoue M, Kawano S, et al. Risk factors associated with local recurrence of early gastric cancers after endoscopic submucosal dissection. Gastrointest Endosc. 2008;68:887-94.

23. Okada K, Fujisaki J, Kasuga A, Omae M, Yoshimoto K, Hirasawa $\mathrm{T}$, et al. Endoscopic ultrasonography is valuable for identifying early gastric cancers meeting expanded-indication criteria for endoscopic submucosal dissection. Surg Endosc. 2011;25: $841-8$.

24. Chonan A, Mishima T, Miyake N, Ishibashi J, Nakahori M, Matsuda T, et al. Endoscopic ultrasonographic diagnosis of depth of invasion of early gastric cancer [in Japanese with English abstract]. Stomach Intest (Tokyo). 2009;44:623-35.

25. Isomoto H, Shikuwa S, Yamaguchi N, Fukuda E, Ikeda K, Nishiyama $\mathrm{H}$, et al. Endoscopic submucosal dissection for early gastric cancer: a large-scale feasibility study. Gut. 2009;58: $331-6$. 
26. Fujishiro M, Yahagi N, Kakushima N, Kodashima S, Muraki Y, Ono $\mathrm{S}$, et al. Successful nonsurgical management of perforation complicating endoscopic submucosal dissection of gastrointestinal epithelial neoplasms. Endoscopy. 2006;38:1001-6.

27. Yano H, Kimura Y, Iwazawa T, Monden T. Laparoscopic management for local recurrence of early gastric cancer after endoscopic mucosal resection. Surg Endosc. 2005;19:981-5.

28. Tonouchi H, Mohri Y, Kobayashi M, Tanaka K, Ohi M, Kusunoki M. Laparoscopy-assisted distal gastrectomy with laparoscopic sentinel lymph node biopsy after endoscopic mucosal resection for early gastric cancer. Surg Endosc. 2007;21:1289-93.

29. Koide N, Takeuchi D, Suzuki A, Ishizone S, Miyagawa S. Additional gastrectomy after endoscopic submucosal dissection for early gastric cancer patients with comorbidities. Int J Surg Oncol. doi:10.1155/2012/379210. 